\title{
Selection of Salt Tolerant Somaclones for Development of Salt Stress Tolerant Varieties
}

\author{
Mst. Kohinoor Begum ${ }^{1}$, Md. Obaidul Islam ${ }^{2, *}$ \\ ${ }^{1}$ Bangladesh Sugarcane Research Institute, Pabna, Bangladesh \\ ${ }^{2}$ Dept. of Crop Botany, Bangladesh Agricultural University, Mymensingh, Bangladesh
}

Email address:

kohinoorsamia@yahoo.com (Mst. K. Begum)

\section{To cite this article:}

Mst. Kohinoor Begum, Md. Obaidul Islam. Selection of Salt Tolerant Somaclones for Development of Salt Stress Tolerant Varieties. Plant. Vol. 3, No. 4, 2015, pp. 37-46. doi: 10.11648/j.plant.20150304.12

\begin{abstract}
The experiment were carried out at the farm of Bangladesh Sugarcane Research Institute Ishurdi, Pabna, Bangladesh during 2011-2012 cropping season. The somaclones which were produced in vitro under salinity stress evaluated in the field and after 1st year evaluation those which showed better performance were selected for this experiment to select salinity tolerant line of sugarcane. Sugarcane varieties Isd 28, Isd 35, Isd 36, Isd 37 and Isd 38 were used for selection of salinity tolerant lines. As treatments, salt were used with MS medium for in vitro plantlet regeneration. The selected somaclones were evaluated in $1^{\text {st }}$ and $2^{\text {nd }}$ year and after $1^{\text {st }}$ year evaluation better somaclones were also evaluated under induced salinity stress conditions using different levels of salt $(50 \mathrm{mM}, 100 \mathrm{mM} \& 150 \mathrm{mM})$. Molecular characterizations were also done with the setts of selected somaclones collected from R2 generation. At the highest level of salinity $(150 \mathrm{mM})$ varieties Isd 35 and Isd 37 initiated callus. Under induced salinity stress SC3 of Isd 28, SC3 of Isd 35 and SC2, SC3 of Isd 37 showed better performance in PVC pipe. Those somaclones also performed better in morpho-physiological performance at field condition in two sequential years and also produced polymorphic bands when we characterized with SSR marker. So those lines should be considered as salinity tolerant lines for further study.
\end{abstract}

Keywords: Somaclone, Sugarcane, Salinity Stress, Proline, Molecular Characterization

\section{Introduction}

The Environment Program of United Nations estimated that approximately $20 \%$ of the world's agricultural land and nearly $50 \%$ of all irrigated land is adversely affected by soil salinity (Flowers and Yeo, 1995). It is a general problem worldwide, but most acute in North and Central Asia, Australia and South America (Pessarakli, 1999). Some of the most serious problems occur in semi-arid regions associated with the great river systems of South-East Asia. In Bangladesh, over 30\% of the net cultivable area lies in the coastal zone of Bay of Bengal, of which approximately $53 \%$ is affected by varying degrees of salinity. The salt affected area in the coastal zone of the country was about 0.83 million ha in 1966-76, which expanded to 3.1 million ha over the last two decades (Kader, 2006). In addition, more area in that zone is expected to become saline affected in future due to increase in sea water level as a consequence of the greenhouse effect. The other concern is that the area under irrigation is increasing worldwide day-byday allowing more area to be affected by salinity stress. As estimated by FAO, about 20-30 million ha of irrigated lands worldwide were seriously damaged in 2002 due to the build-up of salts and every year $0.25-0.50$ million ha of irrigated lands worldwide are lost from production due to salts build-up (Martinez-Beltran and Manzur, 2005).

To meet the future requirement of sugar it is essential to develop some improved varieties, suitable for the agronomic conditions of Bangladesh within shorter period. Plant regeneration protocols for different varieties of sugarcane are the prerequisite for the tissue culture derived plantlet production. It is claimed that if cell can adapt to a high salinity it could give rise to a plant which is similarly stress tolerant (Gollek, 1973). Variation in differentiation ability in Saccharum spp. has been reported earlier (Liu et al., 1972, Bhansali and Kishan, 1982). Considering enrichment of sugarcane productivity in saline areas as well as minimize total demand of sugar, regeneration of salt tolerant sugarcane varieties is essential. The present study of stress tolerance of 
sugarcane in vitro helps to understand the basic phenomenon of the stress and facilitate the development of varieties tolerant to salinity.

Somaclonal variation had produced desirable agronomic changes in the progeny and increased sugar yield in sugarcane (Evans et. al., 1984). Variation in differentiation ability in Saccharum spp. has been reported elsewhere (Bhansali and Kishan, 1982). In vitro regeneration of sugarcane has also been reported (Heinz et al., 1995). Increasing population and changing climatic conditions of our country have long been demanding higher sugar producing and stress prone somaclone / cultivar. To meet these demand, development of sugarcane variety having tolerance to water logging, drought and salinity have received more research attention in recent years. Evaluation and characterization of the spontaneous and induced variants against salinity and drought may prove highly fruitful venture for its successful cultivation in stress conditions. Therefore, analysis of the induced and spontaneous genetic variation in the regenerated plants is necessary for exploiting these variants for crop improvement. Simple Sequence Repeats (SSRs), were adopted for evaluation of clonal fidelity in sugarcane plantlets. The microsatellite markers developed from the genomic sequences are reported to be more polymorphic than ESTs-derived markers and are thus suitable for various genotyping applications in sugarcane (Singh et al., 2011). The objectives of the present study are Performance evaluation of R2 somaclones under induced salinity stress condition of PVC pipe; and Marker aided characterization of R2 generation for selecting salinity stress tolerant lines.

\section{Materials and Methods}

Five sugarcane varieties viz. Isd 28, Isd 35, Isd 36, Isd 37 and Isd 38 were used as plant material. In vitro healthy and rooted plantlets which were produced under salinity stress were selected for 1 st year valuation and after 1 st year evaluation the better somaclones were planted in PVC pipe with different salinity stress treatments.

After taking the harvesting data at the end of first year the healthy stalks were used for preparation of polybag settlings for R2 generation study (in 2nd year) in PVC pipe under induced salinity stress. For polybag settlings, the cane stalks were cut into small pieces $(5 \mathrm{~cm})$ containing one bud each with at least $1.5 \mathrm{~cm}$ stalk on above the node and about $3 \mathrm{~cm}$ at below. All setts were treated by Bavistin solution (1:1000) for 30 minutes to prevent fungal infection. Polybags of 12.5 $\mathrm{cm} \times 10.0 \mathrm{~cm}$ size were taken and four holes were made at the bottom of the bags to drain out the excess water. The soil for filling polybags was mixed with cowdung $(1: 1)$ and then treated with Chlorpyrifos (Regent 3 GR)@ 0.04 g bag-1 and Carbofuran (Furadan 5G)@0.05g bag-1 to control insect pest in the nursery. About $2 / 3$ rds of polybag were filled with the mixed soil and a previously treated sett was placed vertically in the centre of soil of the bag keeping the bud in upward direction. Then the polybag was completely filled with the soil so that about $1.5-2.0 \mathrm{~cm}$ soil covered the setts.
The polybags were kept in a sunny place and also covered with rice straw thinly to preserve soil moisture, and protect soil loss from heavy rain (Ali et al., 1989). Watering was done at 2 days interval to the nursery beds throughout the whole period before transplantation. Other cultural operations like weeding, rouging of diseased and pest infected settlings were done to maintain healthy settlings. The polybag settlings which were prepared earlier from R1 generation were transplanted in PVC pipes under induced salinity stresses. The salinity levels of $\mathrm{PVC}$ pipes were $50,100 \& 150 \mathrm{mM}$ (created by $\mathrm{NaCl}, \mathrm{Na} 2 \mathrm{SO} 4, \mathrm{NaHCO} 3$, $\mathrm{CaCl} 2, \mathrm{MgCl} 2$ and $\mathrm{MgSO} 4$ followed by the procedure of SRDI, 2003). Plantlets were transplanted on 02.02.12 in PVC pipes containing soils and pressmud at 3:2 ratio. The soilspressmud mixture of each PVC pipe was fertilized at the rate of 4, 3 and $3 \mathrm{~g}$ of urea, TSP and MP, respectively. Full TSP, MP and $2 \mathrm{~g}$ urea were applied in each pit as basal dose at planting time and the rest $(1.0 \mathrm{~g}+1.0 \mathrm{~g})$ of urea was applied as top dressing in two equal splits at 45 and 75 days after planting. First irrigation was applied just after the plantation of plantlets for good establishment and second and third irrigation were applied at 30 days and 60 days after transplantation (DAT). No insecticides were applied. In the month of June-July few stem borer infestation was observed and soon preventive measures like collecting adult moths by net, destroying egg mass and cutting the top of the affected plants to kill larvae were taken. Weeding was done when needed.

\subsection{Data Collection from Plants Grown in PVC Pipes under R2 Generation}

Data on stalk height $(\mathrm{m})$, proline $(\mathrm{mg} / \mathrm{g})$ content, total dry wt. (g/cane) and shoot root ratio were collected from plants grown in PVC pipes. In case of induced salinity stress condition $\mathrm{Na}+, \mathrm{K}+, \mathrm{Ca}+, \mathrm{Mg}+$ and $\mathrm{Cl}-(\mathrm{mg} / \mathrm{g})$ were also determined.

The collected data were analyzed following factorial Completely Randomized Block Design (CRBD) using computer software MSTAT-C. The analysis of variance was performed and means were compared by Duncan's New Multiple Range Test (DNMRT) at $5 \%$ level of probability.

\subsection{DNA Collection from Samples of R2 Generation and Amplification by PCR Using SSR Markers}

In the present investigation, method adopted from Shahanawaz (2006) has been used to isolate the total genomic DNA of twenty eight somaclones of R2 generation and their mother plants.

Following electrophoresis, the size of amplification products were estimated by comparing the migration of each amplified fragment with that of a known size fragments of molecular weight marker 100bp DNA ladder. All distinct bands or fragments were thereby given identification numbers according to their position on the gel and scored visually on the basis of their presence (1) or absence (0), separately for each individual and each primer. 


\section{Results}

\subsection{Biochemical Performance of Selected R1 Somaclones under Different Levels of Salinity in PVC Pipe}

\subsubsection{Proline}

Proline content both in mother clone and somaclones differed significantly under salinity stress in PVC pipes (Table 1). The somaclones of Isd 28 obtained the highest proline level and the lowest content was in mother clone. Similar trend was observed in Isd 37. The proline level in Isd 38 and Isd 35 was the highest in SC3 and the lowest was in SC1. In Isd 36, the highest proline level was observed in SC2 followed by SC1 and the lowest was in SC3 (Table 1).

Table 1. Effects of clones/somaclones on proline in R2 generation.

\begin{tabular}{llllll}
\hline \multirow{2}{*}{$\begin{array}{l}\text { Name of } \\
\text { somaclones }\end{array}$} & \multicolumn{4}{l}{ Proline $\left(\mathbf{m g g}^{-1}\right)$} \\
\cline { 2 - 6 } & Isd 28 & Isd 35 & Isd 36 & Isd 37 & Isd 38 \\
\hline Mother & $0.3367 \mathrm{~b}$ & $0.278 \mathrm{~b}$ & $.238 \mathrm{~d}$ & $.490 \mathrm{~b}$ & $.263 \mathrm{~d}$ \\
$\mathrm{SC} 1$ & $0.4045 \mathrm{a}$ & $0.272 \mathrm{c}$ & $.266 \mathrm{~b}$ & $.515 \mathrm{ab}$ & $.270 \mathrm{c}$ \\
$\mathrm{SC} 2$ & $0.4238 \mathrm{a}$ & $0.279 \mathrm{~b}$ & $.285 \mathrm{a}$ & $.512 \mathrm{ab}$ & $.279 \mathrm{~b}$ \\
$\mathrm{SC} 3$ & $0.4234 \mathrm{a}$ & $0.289 \mathrm{a}$ & $.260 \mathrm{c}$ & $.533 \mathrm{a}$ & $.298 \mathrm{a}$ \\
LSD (0.05) & 0.02630 & 0.002630 & .002630 & .03719 & .002630 \\
\hline
\end{tabular}

Table 2. ffects of salinity level on proline of clones/somaclones in $R 2$ generation.

\begin{tabular}{llllll}
\hline $\begin{array}{l}\text { Salinity } \\
\text { level (mM) }\end{array}$ & \multicolumn{4}{l}{ Proline $\left(\mathbf{m g g}^{-1}\right)$} & \\
\cline { 2 - 6 } & Isd 28 & Isd 35 & Isd 36 & Isd 37 & Isd 38 \\
\hline 0 & $0.2157 \mathrm{~d}$ & $0.229 \mathrm{~d}$ & $.206 \mathrm{~d}$ & $.470 \mathrm{c}$ & $.228 \mathrm{~d}$ \\
50 & $0.3480 \mathrm{c}$ & $0.267 \mathrm{c}$ & $.240 \mathrm{c}$ & $.497 \mathrm{bc}$ & $.259 \mathrm{c}$ \\
100 & $0.4821 \mathrm{~b}$ & $0.293 \mathrm{~b}$ & $.282 \mathrm{~b}$ & $.531 \mathrm{ab}$ & $.290 \mathrm{~b}$ \\
150 & $0.5828 \mathrm{a}$ & $0.328 \mathrm{a}$ & $.321 \mathrm{a}$ & $.550 \mathrm{a}$ & $.334 \mathrm{a}$ \\
LSD $(0.05)$ & 0.02630 & 0.002630 & .002630 & .03719 & .002630 \\
\hline
\end{tabular}

In case of all somaclones of different varieties the proline levels were the highest under highest level of salinity in PVC pipes (Table 2). The lowest proline content was observed in control in all varieties. Isd 28 and Isd 37 showed higher level of proline than other varieties.

Interaction effect of mother clones and somaclones to different salinity levels in PVC pipes is presented in Table 3 In all somaclones of different varieties the proline levels increased with gradually increase of salinity levels. At control (0 $\mathrm{mM}$ salt), proline content was higher in somaclones over mother clone in Isd 28. Similarly at 50 $\mathrm{mM}$ levels of salinity, significantly higher proline levels were observed in somaclones compared to mother clones of Isd 28. In Isd 35, somaclones SC3 had significantly higher proline content at $150 \mathrm{mM}$ salinity levels compared to respective mother clones (Table 3). At $100 \mathrm{mM}$ salinity level the highest proline level was observed in SC2 followed by $\mathrm{SC} 1$ and mother and the lowest level was in SC3. In Isd 36, the highest proline level was in SC2 at 150 $\mathrm{mM}$ level and the lowest was in mother clone in control. In Isd 37, almost all somaclones showed higher proline at lower and higher levels of salinity. Somaclone 3 of Isd 38 showed the highest level of proline at $150 \mathrm{mM}$ salinity level followed by $\mathrm{SC} 2$ at same salinity level and the lowest proline was observed in mother clones at $0 \mathrm{mM}$ salt level. Thus it was evident that the proline level was higher in higher level of salinity and almost all somaclones showed better proline synthesis under salinity stress as well as in normal soil condition in sugarcane.

Table 3. Interaction effects of clones/somaclones to salinity level on proline in R2 generation .

\begin{tabular}{|c|c|c|c|c|c|}
\hline \multirow{2}{*}{$\begin{array}{l}\text { Clones/ } \\
\text { somaclonesx } \\
\text { Salinity level } \\
(\mathrm{mM})\end{array}$} & \multicolumn{5}{|c|}{ Proline(mgg $\left.{ }^{-1}\right)$} \\
\hline & Isd 28 & Isd 35 & Isd 36 & Isd 37 & Isd 38 \\
\hline Mother $\times 0$ & $.201 \mathrm{f}$ & $.244 \mathrm{~h}$ & $.199 \mathrm{~g}$ & $.483 \mathrm{ab}$ & $.201 \mathrm{k}$ \\
\hline Mother $\times 50$ & $.312 \mathrm{e}$ & $.268 \mathrm{f}$ & $.213 \mathrm{e}$ & $.431 \mathrm{bc}$ & $.249 \mathrm{~h}$ \\
\hline Mother $\times 100$ & $.443 \mathrm{~d}$ & $.291 \mathrm{~d}$ & $.250 \mathrm{~d}$ & $.511 \mathrm{ab}$ & $.291 \mathrm{f}$ \\
\hline Mother $\times 150$ & $.551 \mathrm{ab}$ & $.310 \mathrm{~b}$ & $.290 \mathrm{c}$ & $.532 \mathrm{a}$ & $.311 \mathrm{~d}$ \\
\hline $\mathrm{SC} 1 \times 0$ & $.210 \mathrm{f}$ & $.223 \mathrm{j}$ & $.213 \mathrm{e}$ & $.491 \mathrm{ab}$ & $.225 \mathrm{j}$ \\
\hline $\mathrm{SC} 1 \times 50$ & $.352 \mathrm{e}$ & $.270 \mathrm{f}$ & $.250 \mathrm{~d}$ & $.503 \mathrm{ab}$ & $.251 \mathrm{~h}$ \\
\hline $\mathrm{SC} 1 \times 100$ & $.475 \mathrm{~cd}$ & $.297 \mathrm{c}$ & $.298 \mathrm{~b}$ & $.521 \mathrm{a}$ & $.281 \mathrm{~g}$ \\
\hline $\mathrm{SC} 1 \times 150$ & $.591 \mathrm{a}$ & $.297 \mathrm{c}$ & $.301 \mathrm{~b}$ & $.543 \mathrm{a}$ & $.323 \mathrm{c}$ \\
\hline $\mathrm{SC} 2 \times 0$ & $.224 \mathrm{f}$ & $.231 \mathrm{i}$ & $.205 \mathrm{f}$ & $.501 \mathrm{c}$ & $.237 \mathrm{i}$ \\
\hline $\mathrm{SC} 2 \times 50$ & $.361 \mathrm{e}$ & $.281 \mathrm{e}$ & $.250 \mathrm{~d}$ & $.532 \mathrm{a}$ & $.253 \mathrm{~h}$ \\
\hline $\mathrm{SC} 2 \times 100$ & $.482 \mathrm{bc}$ & $.298 \mathrm{c}$ & $.291 \mathrm{c}$ & $.551 \mathrm{a}$ & $.291 \mathrm{f}$ \\
\hline $\mathrm{SC} 2 \times 150$ & $.595 \mathrm{a}$ & $.305 \mathrm{~b}$ & $.393 \mathrm{a}$ & $.563 \mathrm{a}$ & $.335 \mathrm{~b}$ \\
\hline $\mathrm{SC} 3 \times 0$ & $.231 \mathrm{f}$ & $.219 \mathrm{j}$ & $.207 \mathrm{f}$ & $.505 \mathrm{ab}$ & $.248 \mathrm{~h}$ \\
\hline $\mathrm{SC} 3 \times 50$ & $.367 \mathrm{e}$ & $.250 \mathrm{~g}$ & $.248 \mathrm{~d}$ & $.523 \mathrm{a}$ & $.281 \mathrm{~g}$ \\
\hline $\mathrm{SC} 3 \times 100$ & $.495 \mathrm{~cd}$ & $.287 \mathrm{~d}$ & $.287 \mathrm{c}$ & $.541 \mathrm{a}$ & $.298 \mathrm{e}$ \\
\hline $\mathrm{SC} 3 \times 150$ & $.601 \mathrm{a}$ & $.398 \mathrm{a}$ & $.298 \mathrm{~b}$ & $.563 \mathrm{a}$ & $.366 \mathrm{a}$ \\
\hline $\operatorname{LSD}(0.05)$ & .05259 & .005259 & .005259 & .07438 & .005259 \\
\hline
\end{tabular}

Figures with similar letter (s) don't differ significantly at $5.0 \%$ probability by DMRT

\subsection{2. $\mathrm{Na}^{+}$of Shoot}

Mother clones and all the selected somaclones showed significant effects on $\mathrm{Na}^{+}$content in shoot (Table 4). Mother clones of all the varieties showed higher level of $\mathrm{Na}+$ than their somaclones. In Isd 28, all the somaclones showed insignificant difference and the lowest level of $\mathrm{Na}+$ content in shoot. In Isd 35, SC2 showed the lowest level of $\mathrm{Na}+$ content. Similar trend was observed in Isd 38. In Isd 36 and Isd 37, SC1 showed the lowest level of $\mathrm{Na}+$ content. Trend of increasing $\mathrm{Na}+$ content as observed with the increasing level of salinity (Table 5). The highest $\mathrm{Na}+$ content was observed when the highest salinity level was imposed with salt. No significant difference was observed at 100 and $150 \mathrm{mM}$ level of salinity in Isd 36. Interaction effects of selected somaclones to salinity levels revealed that in all lines gradual increased level of salt were increased $\mathrm{Na}+$ content (Table 6). At $150 \mathrm{mM}$ level of salinity the highest $\mathrm{Na}+$ content was observed in mother clone followed by SC3 of Isd 28. Similar trend was observed in Isd 35, Isd 37 and Isd 38. In Isd 36, somaclones SC2 and SC3 showed no significant difference and showed lower level of $\mathrm{Na}+$ content at $150 \mathrm{mM}$ level of salinity. 
Table 4. Effects of clones/somaclones on $\mathrm{Na}^{+}$of shoot in $\mathrm{R} 2$ generation in PVC pipe.

\begin{tabular}{llllll}
\hline Name of & \multicolumn{5}{l}{$\mathbf{N a}^{+}\left(\mathbf{m g g}^{-1}\right)$ in shoot } \\
somaclones & Isd 28 & Isd 35 & Isd 36 & Isd 37 & Isd 38 \\
\hline Mother & $0.95 \mathrm{a}$ & $1.05 \mathrm{a}$ & $1.02 \mathrm{a}$ & $0.89 \mathrm{a}$ & $0.99 \mathrm{a}$ \\
SC1 & $0.71 \mathrm{~b}$ & $0.83 \mathrm{~b}$ & $0.55 \mathrm{c}$ & $0.75 \mathrm{c}$ & $0.74 \mathrm{bc}$ \\
SC2 & $0.68 \mathrm{~b}$ & $0.77 \mathrm{c}$ & $0.71 \mathrm{~b}$ & $0.81 \mathrm{~b}$ & $0.70 \mathrm{c}$ \\
SC3 & $0.73 \mathrm{~b}$ & $0.79 \mathrm{bc}$ & $0.72 \mathrm{~b}$ & $0.80 \mathrm{bc}$ & $0.76 \mathrm{~b}$ \\
LSD (0.05) & 0.06 & 0.05 & 0.05 & 0.05 & 0.04 \\
\hline
\end{tabular}

Table 5. Effects of salinity level on $\mathrm{Na}^{+}\left(\mathrm{mgg}^{-1}\right)$ of shoot of in $\mathrm{R} 2$ generation.

Table 6. Interaction effects of clones/somaclones to salinity level on $\mathrm{Na}^{+}$of shoot in $\mathrm{R} 2$ generation.

\begin{tabular}{|c|c|c|c|c|c|}
\hline \multirow{2}{*}{$\begin{array}{l}\text { Clones/somaclones x } \\
\text { Salinity level }(\mathrm{mM})\end{array}$} & \multicolumn{5}{|c|}{$\mathrm{Na}^{+}\left(\mathrm{mgg}^{-1}\right)$ in shoot } \\
\hline & Isd 28 & Isd 35 & Isd 36 & Isd 37 & Isd 38 \\
\hline Mother $\times 0$ & $.31 \mathrm{f}$ & $.43 \mathrm{~h}$ & $.41 \mathrm{~h}$ & $.32 \mathrm{~h}$ & $.36 \mathrm{~h}$ \\
\hline Mother $\times 50$ & $.92 \mathrm{~cd}$ & $.97 \mathrm{c}$ & $.98 \mathrm{c}$ & $.97 \mathrm{de}$ & $.95 \mathrm{~cd}$ \\
\hline Mother $\times 100$ & $1.07 \mathrm{~b}$ & $1.16 \mathrm{~b}$ & $1.10 \mathrm{~b}$ & $1.03 \mathrm{~cd}$ & $1.10 \mathrm{~b}$ \\
\hline Mother $\times 150$ & $1.50 \mathrm{a}$ & $1.62 \mathrm{a}$ & $1.60 \mathrm{a}$ & $1.23 \mathrm{a}$ & $1.54 \mathrm{a}$ \\
\hline $\mathrm{SC} 1 \times 0$ & $.28 \mathrm{f}$ & $.39 \mathrm{~h}$ & $.36 \mathrm{~h}$ & $.27 \mathrm{~h}$ & $.33 \mathrm{~h}$ \\
\hline $\mathrm{SC} 1 \times 50$ & $.60 \mathrm{e}$ & $.75 \mathrm{fg}$ & $.81 \mathrm{ef}$ & $.71 \mathrm{~g}$ & $.79 \mathrm{fg}$ \\
\hline $\mathrm{SC} 1 \times 100$ & $.92 \mathrm{~cd}$ & $.94 \mathrm{~cd}$ & $.93 \mathrm{~cd}$ & .89 ef & $.88 \mathrm{def}$ \\
\hline $\mathrm{SC} 1 \times 150$ & $1.02 \mathrm{bc}$ & $1.24 \mathrm{~b}$ & $.113 \mathrm{i}$ & $1.11 \mathrm{bc}$ & $.97 \mathrm{~cd}$ \\
\hline $\mathrm{SC} 2 \times 0$ & $.27 \mathrm{f}$ & $.33 \mathrm{~h}$ & $.31 \mathrm{~h}$ & $.29 \mathrm{~h}$ & $.31 \mathrm{~h}$ \\
\hline $\mathrm{SC} 2 \times 50$ & $.58 \mathrm{e}$ & $.71 \mathrm{~g}$ & $.72 \mathrm{fg}$ & $.81 \mathrm{fg}$ & $.76 \mathrm{~g}$ \\
\hline $\mathrm{SC} 2 \times 100$ & $.87 \mathrm{~d}$ & .87 cde & $.83 \mathrm{def}$ & $.98 \mathrm{de}$ & $.83 \mathrm{efg}$ \\
\hline $\mathrm{SC} 2 \times 150$ & $.99 \mathrm{bcd}$ & $1.17 \mathrm{~b}$ & $.97 \mathrm{c}$ & $1.15 \mathrm{ab}$ & $.91 \mathrm{de}$ \\
\hline $\mathrm{SC} 3 \times 0$ & $.29 \mathrm{f}$ & $.35 \mathrm{~h}$ & $.34 \mathrm{~h}$ & $.30 \mathrm{~h}$ & $.34 \mathrm{~h}$ \\
\hline $\mathrm{SC} 3 \times 50$ & $.60 \mathrm{e}$ & $.77 \mathrm{efg}$ & $.68 \mathrm{~g}$ & $.77 \mathrm{~g}$ & $.78 \mathrm{~g}$ \\
\hline $\mathrm{SC} 3 \times 100$ & $.93 \mathrm{~cd}$ & $.85 \mathrm{def}$ & .89 cde & $.93 \mathrm{de}$ & $.91 \mathrm{de}$ \\
\hline $\mathrm{SC} 3 \times 150$ & $1.10 \mathrm{~b}$ & $1.20 \mathrm{~b}$ & $.98 \mathrm{c}$ & $1.17 \mathrm{ab}$ & $1.02 \mathrm{bc}$ \\
\hline $\operatorname{LSD}(0.05)$ & 0.1288 & 0.1052 & 0.1052 & 0.1052 & 0.09109 \\
\hline
\end{tabular}

Figures with similar letter (s) don't differ significantly at 5.0\% probability by DMRT

\subsection{3. $\mathrm{Na}^{+}$of Root}

Mother clones and all the selected somaclones differed significantly on $\mathrm{Na}+$ content in root (Table 7). Mother clones of all the varieties showed higher level of $\mathrm{Na}+$ than their somaclones. In Isd 28, SC3 showed the lowest level of $\mathrm{Na}+$ content in root followed by SC1. In Isd 35, SC1 showed the lowest level of $\mathrm{Na}+$ content followed by other two. Similar trend was observed in Isd 37. In Isd 36, all the somaclones showed insignificant difference and lower level of $\mathrm{Na}^{+}$ content than their mother. In Isd 38, SC2 showed the lowest level of $\mathrm{Na}+$ content. Trend of increasing $\mathrm{Na}+$ content was observed with the increasing level of salinity (Table 8). The highest $\mathrm{Na}+$ content in root was observed when highest salinity level was imposed with salt. Interaction effects of selected somaclones to salinity levels revealed that in all lines gradual increased level of salt were increased $\mathrm{Na}+$ content (Table 9). At $150 \mathrm{mM}$ level of salinity the highest $\mathrm{Na}+$ content was observed in mother clone followed by $\mathrm{SC} 1$ of Isd 28. In Isd 35 at $150 \mathrm{mM}$ level of salinity, SC2 and SC3 showed no significant difference with their mother and SC1 showed lower $\mathrm{Na}+$ content. In Isd 36, all the somaclones showed no significant difference and lower level of $\mathrm{Na}+$ content than their mother at $150 \mathrm{mM}$ level of salinity. Somaclones 2 and 3 showed no significant difference at 150

\begin{tabular}{|c|c|c|c|c|c|}
\hline \multirow{2}{*}{$\begin{array}{l}\text { Salinity } \\
\text { level (mM) }\end{array}$} & \multicolumn{5}{|c|}{$\mathrm{Na}^{+}\left(\mathrm{mgg}^{-1}\right)$ in shoot } \\
\hline & Isd 28 & Isd 35 & Isd 36 & Isd 37 & Isd 38 \\
\hline 0 & $0.29 \mathrm{~d}$ & $.38 \mathrm{~d}$ & $.36 \mathrm{c}$ & $.30 \mathrm{~d}$ & $.34 \mathrm{~d}$ \\
\hline 50 & $0.68 \mathrm{c}$ & $.80 \mathrm{c}$ & $.80 \mathrm{~b}$ & $.82 \mathrm{c}$ & $.82 \mathrm{c}$ \\
\hline 100 & $0.95 \mathrm{~b}$ & $.96 \mathrm{~b}$ & $.94 \mathrm{a}$ & $.96 b$ & $.93 \mathrm{~b}$ \\
\hline 150 & $1.15 \mathrm{a}$ & $1.31 \mathrm{a}$ & $.92 \mathrm{a}$ & $1.17 \mathrm{a}$ & $1.11 \mathrm{a}$ \\
\hline $\operatorname{LSD}(0.05)$ & 0.06 & .053 & .053 & .053 & .046 \\
\hline
\end{tabular}

$\mathrm{mM}$ level of salinity with mother clone and $\mathrm{SC} 1$ showed lower $\mathrm{Na}+$ content in root in Isd 37. The highest level of $\mathrm{Na}+$ content in root at $150 \mathrm{mM}$ level of salinity was observed in mother clone followed by SC3 in Isd 38 .

Table 7. Effects of clones/somaclones on $\mathrm{Na}^{+}$of root in $\mathrm{R} 2$ generation in PVC pipe.

\begin{tabular}{|c|c|c|c|c|c|}
\hline \multirow{2}{*}{$\begin{array}{l}\text { Name of } \\
\text { somaclones }\end{array}$} & \multicolumn{5}{|c|}{$\mathrm{Na}^{+}\left(\mathrm{mgg}^{-1}\right)$ in root } \\
\hline & Isd 28 & Isd 35 & Isd 36 & Isd 37 & Isd 38 \\
\hline Mother & $0.71 \mathrm{a}$ & $0.80 \mathrm{a}$ & $0.81 \mathrm{a}$ & $0.82 \mathrm{a}$ & $0.84 \mathrm{a}$ \\
\hline $\mathrm{SC} 1$ & $0.62 b$ & $0.67 \mathrm{c}$ & $0.70 \mathrm{~b}$ & $0.69 \mathrm{c}$ & $0.67 \mathrm{~b}$ \\
\hline $\mathrm{SC} 2$ & $0.59 \mathrm{bc}$ & $0.75 \mathrm{~b}$ & $0.66 \mathrm{~b}$ & $0.77 \mathrm{~b}$ & $0.62 \mathrm{c}$ \\
\hline $\mathrm{SC} 3$ & $0.56 \mathrm{c}$ & $0.74 \mathrm{~b}$ & $0.65 \mathrm{~b}$ & $0.76 \mathrm{~b}$ & $0.66 \mathrm{~b}$ \\
\hline LSD (0.05) & 0.05 & 0.04 & 0.04 & 0.04 & 0.03 \\
\hline
\end{tabular}

Table 8. Effects of salinity level on $\mathrm{Na}^{+}$of root in $\mathrm{R} 2$ generation.

\begin{tabular}{|c|c|c|c|c|c|}
\hline \multirow{2}{*}{$\begin{array}{l}\text { Salinity } \\
\text { level (mM) }\end{array}$} & \multicolumn{5}{|c|}{$\mathrm{Na}^{+}\left(\mathrm{mgg}^{-1}\right)$ in root } \\
\hline & Isd 28 & Isd 35 & Isd 36 & Isd 37 & Isd 38 \\
\hline 0 & $0.34 d$ & $.41 \mathrm{~d}$ & $.31 \mathrm{~d}$ & $.368 \mathrm{~d}$ & $.41 \mathrm{~d}$ \\
\hline 50 & $0.48 \mathrm{c}$ & $.64 \mathrm{c}$ & $.67 \mathrm{c}$ & $.738 \mathrm{c}$ & $.61 \mathrm{c}$ \\
\hline 100 & $0.72 \mathrm{~b}$ & $.84 \mathrm{~b}$ & $.83 \mathrm{~b}$ & $.895 \mathrm{~b}$ & $.8 \mathrm{~b}$ \\
\hline 150 & $0.93 \mathrm{a}$ & $1.07 \mathrm{a}$ & $1.023 \mathrm{a}$ & $1.04 \mathrm{a}$ & $.99 \mathrm{a}$ \\
\hline $\operatorname{LSD}(0.05)$ & 0.05 & 0.04 & 0.04 & 0.04 & 0.03 \\
\hline
\end{tabular}


Table 9. Interaction effects of clones/somaclones to salinity level on $\mathrm{Na}^{+}$of root in $\mathrm{R} 2$ generation.

\begin{tabular}{|c|c|c|c|c|c|}
\hline \multirow{2}{*}{$\begin{array}{l}\text { Clones/somaclones x } \\
\text { Salinity level (mM) }\end{array}$} & \multicolumn{5}{|c|}{$\mathrm{Na}^{+}\left(\mathrm{mgg}^{-1}\right)$ in root } \\
\hline & Isd 28 & Isd 35 & Isd 36 & Isd 37 & Isd 38 \\
\hline Mother $\times 0$ & $.347 \mathrm{jk}$ & $.48 \mathrm{~g}$ & $.44 \mathrm{~h}$ & $.41 \mathrm{i}$ & $.44 \mathrm{~h}$ \\
\hline Mother $\times 50$ & $.57 \mathrm{gh}$ & $.61 \mathrm{ef}$ & $.61 \mathrm{~g}$ & $.83 \mathrm{fg}$ & $.66 \mathrm{f}$ \\
\hline Mother $\times 100$ & .80 cde & $.96 \mathrm{~b}$ & $.90 \mathrm{bc}$ & $.98 \mathrm{bcd}$ & $.93 \mathrm{bc}$ \\
\hline Mother $\times 150$ & $1.10 \mathrm{a}$ & $1.15 \mathrm{a}$ & $1.30 \mathrm{a}$ & $1.07 \mathrm{ab}$ & $1.31 \mathrm{a}$ \\
\hline $\mathrm{SC} 1 \times 0$ & $.330 \mathrm{jk}$ & $.41 \mathrm{gh}$ & $.29 \mathrm{i}$ & $.33 \mathrm{i}$ & $.40 \mathrm{~h}$ \\
\hline $\mathrm{SC} 1 \times 50$ & $.507 \mathrm{hi}$ & $.58 \mathrm{f}$ & $.73 \mathrm{def}$ & $.65 \mathrm{~h}$ & $.61 \mathrm{fg}$ \\
\hline $\mathrm{SC} 1 \times 100$ & $.73 \mathrm{def}$ & $.77 \mathrm{~cd}$ & $.81 \mathrm{~cd}$ & $.81 \mathrm{~g}$ & $.75 \mathrm{e}$ \\
\hline $\mathrm{SC} 1 \times 150$ & $.92 \mathrm{~b}$ & $.92 \mathrm{~b}$ & $.95 \mathrm{~b}$ & .96 cde & $.87 \mathrm{~cd}$ \\
\hline $\mathrm{SC} 2 \times 0$ & $.35 \mathrm{jk}$ & $.37 \mathrm{~h}$ & $.27 \mathrm{i}$ & $.37 \mathrm{i}$ & $.41 \mathrm{~h}$ \\
\hline $\mathrm{SC} 2 \times 50$ & $.44 \mathrm{ij}$ & $.69 \mathrm{de}$ & $.69 \mathrm{efg}$ & $.79 \mathrm{~g}$ & $.58 \mathrm{fg}$ \\
\hline $\mathrm{SC} 2 \times 100$ & $.69 \mathrm{ef}$ & $.81 \mathrm{c}$ & $.78 \mathrm{de}$ & $.91 \mathrm{def}$ & $.66 \mathrm{f}$ \\
\hline $\mathrm{SC} 2 \times 150$ & $.86 \mathrm{bc}$ & $1.11 \mathrm{a}$ & $.91 \mathrm{~b}$ & $1.01 \mathrm{abc}$ & $.81 \mathrm{de}$ \\
\hline $\mathrm{SC} 3 \times 0$ & $.32 \mathrm{k}$ & $.38 \mathrm{~h}$ & $.23 \mathrm{i}$ & $.36 \mathrm{i}$ & $.37 \mathrm{~h}$ \\
\hline $\mathrm{SC} 3 \times 50$ & $.41 \mathrm{ijk}$ & $.68 \mathrm{de}$ & $.64 \mathrm{fg}$ & $.68 \mathrm{~h}$ & $.57 \mathrm{~g}$ \\
\hline $\mathrm{SC} 3 \times 100$ & $.67 \mathrm{fg}$ & $.81 \mathrm{c}$ & $.81 \mathrm{~cd}$ & $.88 \mathrm{efg}$ & $.76 \mathrm{e}$ \\
\hline $\mathrm{SC} 3 \times 150$ & $.84 \mathrm{bcd}$ & $1.09 \mathrm{a}$ & $.93 \mathrm{~b}$ & $1.10 \mathrm{a}$ & $.95 \mathrm{~b}$ \\
\hline $\operatorname{LSD}(0.05)$ & 0.11 & 0.09 & 0.09 & 0.09 & 0.07 \\
\hline
\end{tabular}

Figures with similar letter (s) don't differ significantly at $5.0 \%$ probability by DMRT

\subsection{4. $K^{+}$of Shoot}

Mother clones and all the selected somaclones differed significantly on $\mathrm{K}+$ content in shoot (Table 10). Mother clones of all the varieties showed the lowest level of $\mathrm{K}+$ than their somaclones. In Isd 28, SC2 showed the highest level of $\mathrm{K}+$ content in shoot followed by other two. In Isd 35, SC2 and SC3 showed the highest level of $\mathrm{K}+$ content followed by SC1. Similar trend was observed in Isd 38. In Isd 36 and Isd 37, all the somaclones showed insignificant difference and the highest level of $\mathrm{K}+$ content. Trend of decreasing $\mathrm{K}+$ content was observed with the increasing level of salinity (Table 11). Lowest $\mathrm{K}+$ content in shoot was observed when salinity level was the highest. Interaction effects of selected somaclones to salinity levels revealed that in all lines gradual increased level of salt decreased $\mathrm{K}+$ content (Table 12). At $150 \mathrm{mM}$ level of salinity the highest $\mathrm{K}+$ content was observed in $\mathrm{SC} 2$ followed by $\mathrm{SC} 1$ of Isd 28 . In Isd 35 at $150 \mathrm{mM}$ level the highest $\mathrm{K}+$ content was observed in SC2 followed by SC3. Similar trend was observed in Isd 36 Isd 37 and Isd 38.

Table 10. Effects of clones/somaclones on $K^{+}$of shoot in $R 2$ generation in PVC pipe.

\begin{tabular}{|c|c|c|c|c|c|}
\hline \multirow{2}{*}{$\begin{array}{l}\text { Name of } \\
\text { somaclones }\end{array}$} & \multicolumn{5}{|c|}{$\mathrm{K}^{+}\left(\mathrm{mgg}^{-1}\right)$ in shoot } \\
\hline & Isd 28 & Isd 35 & Isd 36 & Isd 37 & Isd 38 \\
\hline Mother & $1.18 \mathrm{c}$ & $1.25 \mathrm{c}$ & $1.06 \mathrm{~b}$ & $1.21 \mathrm{~b}$ & $1.02 \mathrm{c}$ \\
\hline $\mathrm{SC} 1$ & $1.38 \mathrm{ab}$ & $1.35 \mathrm{~b}$ & $1.22 \mathrm{a}$ & $1.39 \mathrm{a}$ & $1.13 \mathrm{~b}$ \\
\hline $\mathrm{SC} 2$ & $1.39 \mathrm{a}$ & $1.51 \mathrm{a}$ & $1.26 \mathrm{a}$ & $1.43 \mathrm{a}$ & $1.22 \mathrm{a}$ \\
\hline $\mathrm{SC} 3$ & $1.30 \mathrm{~b}$ & $1.45 \mathrm{a}$ & $1.24 \mathrm{a}$ & $1.39 \mathrm{a}$ & $1.24 \mathrm{a}$ \\
\hline $\operatorname{LSD}(0.05)$ & 0.07889 & .08316 & .07889 & .07889 & .07438 \\
\hline
\end{tabular}

Table 11. Effects of salinity level on $K^{+}$of shoot in R2 generation

\begin{tabular}{|c|c|c|c|c|c|}
\hline \multirow{2}{*}{$\begin{array}{l}\text { Salinity } \\
\text { level (mM) }\end{array}$} & \multicolumn{5}{|c|}{$\mathrm{K}^{+}\left(\mathrm{mgg}^{-1}\right)$ in shoot } \\
\hline & Isd 28 & Isd 35 & Isd 36 & Isd 37 & Isd 38 \\
\hline 0 & $1.497 \mathrm{a}$ & $1.59 \mathrm{a}$ & $1.36 \mathrm{a}$ & $1.52 \mathrm{a}$ & $1.27 \mathrm{a}$ \\
\hline 50 & $1.335 \mathrm{~b}$ & $1.43 \mathrm{~b}$ & $1.24 \mathrm{~b}$ & $1.38 \mathrm{~b}$ & $1.20 \mathrm{~b}$ \\
\hline 100 & $1.250 \mathrm{c}$ & $1.33 \mathrm{c}$ & $1.15 \mathrm{c}$ & $1.30 \mathrm{c}$ & $1.12 \mathrm{c}$ \\
\hline 150 & $1.138 \mathrm{~d}$ & $1.22 \mathrm{~d}$ & $1.03 \mathrm{~d}$ & $1.21 \mathrm{~d}$ & $1.03 \mathrm{~d}$ \\
\hline $\operatorname{LSD}(0.05)$ & 0.07889 & .08316 & .07889 & .07889 & .07438 \\
\hline
\end{tabular}

Table 12. Interaction effects clones/somaclones to salinity level on $K^{+}$of shoot in $R 2$ generation .

\begin{tabular}{|c|c|c|c|c|c|}
\hline \multirow{2}{*}{$\begin{array}{l}\text { Clones/somaclones } x \\
\text { Salinity level }(\mathrm{mM})\end{array}$} & \multicolumn{5}{|c|}{$\mathrm{K}^{+}\left(\mathrm{mgg}^{-1}\right)$ in shoot } \\
\hline & Isd 28 & Isd 35 & Isd 36 & Isd 37 & Isd 38 \\
\hline Mother $\times 0$ & $1.430 \mathrm{abc}$ & $1.56 \mathrm{ab}$ & $1.28 \mathrm{a}-\mathrm{d}$ & $1.48 \mathrm{abc}$ & $1.20 \mathrm{ab}$ \\
\hline Mother $\times 50$ & $1.200 \mathrm{de}$ & $1.27 \mathrm{def}$ & $1.12 \mathrm{def}$ & $1.23 \mathrm{ef}$ & $1.10 \mathrm{bc}$ \\
\hline Mother $\times 100$ & $1.100 \mathrm{ef}$ & $1.15 \mathrm{efg}$ & $.99 \mathrm{f}$ & $1.12 \mathrm{fg}$ & $.97 \mathrm{c}$ \\
\hline Mother $\times 150$ & $0.9800 \mathrm{f}$ & $1.03 \mathrm{~g}$ & $.83 \mathrm{~g}$ & $.99 \mathrm{~g}$ & $.81 \mathrm{~d}$ \\
\hline $\mathrm{SC} 1 \times 0$ & $1.510 \mathrm{ab}$ & $1.58 \mathrm{ab}$ & $1.36 \mathrm{abc}$ & $1.51 \mathrm{ab}$ & $1.25 \mathrm{ab}$ \\
\hline $\mathrm{SC} 1 \times 50$ & $1.420 \mathrm{abc}$ & $1.42 \mathrm{abcd}$ & $1.24 \mathrm{a}-\mathrm{e}$ & $1.42 \mathrm{a}-\mathrm{d}$ & $1.16 \mathrm{ab}$ \\
\hline $\mathrm{SC} 1 \times 100$ & $1.370 \mathrm{bcd}$ & $1.27 \mathrm{def}$ & $1.19 \mathrm{cde}$ & $1.37 \mathrm{a}-\mathrm{e}$ & $1.10 \mathrm{bc}$ \\
\hline $\mathrm{SC} 1 \times 150$ & $1.213 \mathrm{de}$ & $1.13 \mathrm{fg}$ & $1.07 \mathrm{ef}$ & $1.25 \mathrm{def}$ & $.99 \mathrm{c}$ \\
\hline $\mathrm{SC} 2 \times 0$ & $1.500 \mathrm{abc}$ & $1.61 \mathrm{a}$ & $1.40 \mathrm{a}$ & $1.55 \mathrm{a}$ & $1.31 \mathrm{a}$ \\
\hline $\mathrm{SC} 2 \times 50$ & $1.470 \mathrm{abc}$ & $1.54 \mathrm{ab}$ & $1.33 \mathrm{abc}$ & $1.47 \mathrm{abc}$ & $1.26 \mathrm{ab}$ \\
\hline $\mathrm{SC} 2 \times 100$ & $1.330 \mathrm{bcd}$ & $1.49 \mathrm{abc}$ & $1.20 \mathrm{~b}-\mathrm{e}$ & $1.38 \mathrm{a}-\mathrm{e}$ & $1.19 \mathrm{ab}$ \\
\hline $\mathrm{SC} 2 \times 150$ & $1.240 \mathrm{de}$ & $1.41 \mathrm{bcd}$ & $1.12 \mathrm{def}$ & $1.30 \mathrm{cde}$ & $1.13 \mathrm{bc}$ \\
\hline $\mathrm{SC} 3 \times 0$ & $1.550 \mathrm{a}$ & $1.59 \mathrm{ab}$ & $1.38 \mathrm{ab}$ & $1.53 \mathrm{a}$ & $1.33 \mathrm{a}$ \\
\hline $\mathrm{SC} 3 \times 50$ & $1.330 \mathrm{~cd}$ & $1.48 \mathrm{abc}$ & $1.27 \mathrm{a}-\mathrm{d}$ & $1.41 \mathrm{a}-\mathrm{e}$ & $1.27 \mathrm{ab}$ \\
\hline $\mathrm{SC} 3 \times 100$ & $1.200 \mathrm{de}$ & $1.40 \mathrm{bcd}$ & $1.21 \mathrm{~b}-\mathrm{e}$ & $1.33 \mathrm{~b}-\mathrm{e}$ & $1.21 \mathrm{ab}$ \\
\hline $\mathrm{SC} 3 \times 150$ & $1.120 \mathrm{ef}$ & $1.32 \mathrm{cde}$ & $1.08 \mathrm{ef}$ & $1.28 \mathrm{def}$ & $1.16 \mathrm{ab}$ \\
\hline LSD (0.05) & 0.1578 & 0.1663 & 0.1578 & 0.1578 & 0.1488 \\
\hline
\end{tabular}

Figures with similar letter (s) don’t differ significantly at $5.0 \%$ probability by DMRT 


\subsection{5. $\mathrm{K}^{+}$of Root}

Mother clones and all the selected somaclones differed significantly on $\mathrm{K}^{+}$content in root (Table 13). Mother clones of all the varieties showed the lowest level of $\mathrm{K}^{+}$than their somaclones. In Isd 28 and Isd 37, all the somaclones showed insignificant difference and the highest level of $\mathrm{K}^{+}$content than their mother clone. In Isd 35 and Isd 36, SC2 showed the highest level of $\mathrm{K}^{+}$content in root followed by other two. In Isd 38, SC3 showed highest level of $\mathrm{K}^{+}$content than the other two. Trend of decreasing $\mathrm{K}^{+}$content was observed with the increasing level of salinity (Table 14). Lowest $\mathrm{K}^{+}$content in root was observed when salinity level was the highest in Isd 35, Isd 36 and Isd 37. In Isd 28 and Isd 38, no significant difference was observed in 100 and $150 \mathrm{mM}$ level of salinity. Interaction effects of selected somaclones to salinity levels revealed that in all lines gradual increased level of salt decreased $\mathrm{K}^{+}$content (Table 15). At $150 \mathrm{mM}$ level of salinity the highest $\mathrm{K}^{+}$content was observed in SC3 followed by SC1 of Isd 28. In Isd 35 and Isd 36 at $150 \mathrm{mM}$ level the highest $\mathrm{K}^{+}$content was observed in SC2 followed by SC3. In Isd 37 and Isd 38 at $150 \mathrm{mM}$ level highest $\mathrm{K}^{+}$content was observed in SC3 followed by SC2. Similar trend was observed in Isd 36 Isd 37 and Isd 38.

Table 13. Effects of clones/somaclones on $K^{+}$of root in $R 2$ generation in PVC pipe.

\begin{tabular}{llllll}
\hline \multirow{2}{*}{$\begin{array}{l}\text { Name of } \\
\text { somaclones }\end{array}$} & \multicolumn{4}{l}{$\mathbf{K}^{+}\left(\mathbf{m g g}^{-1}\right)$ in root } \\
\cline { 2 - 6 } & Isd 28 & Isd 35 & Isd 36 & Isd 37 & Isd 38 \\
\hline Mother & $1.40 \mathrm{~b}$ & $1.13 \mathrm{~d}$ & $1.03 \mathrm{c}$ & $1.23 \mathrm{~b}$ & $.80 \mathrm{c}$ \\
$\mathrm{SC} 1$ & $1.54 \mathrm{a}$ & $1.19 \mathrm{c}$ & $1.17 \mathrm{ab}$ & $1.41 \mathrm{a}$ & $1.01 \mathrm{~b}$ \\
$\mathrm{SC} 2$ & $1.52 \mathrm{a}$ & $1.47 \mathrm{a}$ & $1.24 \mathrm{a}$ & $1.40 \mathrm{a}$ & $1.04 \mathrm{~b}$ \\
$\mathrm{SC} 3$ & $1.60 \mathrm{a}$ & $1.35 \mathrm{~b}$ & $1.15 \mathrm{~b}$ & $1.41 \mathrm{a}$ & $1.15 \mathrm{a}$ \\
$\mathrm{LSD}(0.05)$ & 0.07889 & .07889 & .07438 & .08316 & .05880 \\
\hline
\end{tabular}

Table 14. Effects of salinity level on $K^{+}$of root in $R 2$ generation .

\begin{tabular}{llllll}
\hline \multirow{2}{*}{$\begin{array}{l}\text { Salinity } \\
\text { level }(\mathbf{m M})\end{array}$} & \multicolumn{4}{l}{$\mathbf{K}^{+}\left(\mathbf{m g g}^{-1}\right)$ in root } \\
\cline { 2 - 6 } & Isd 28 & Isd 35 & Isd 36 & Isd 37 & Isd 38 \\
\hline 0 & $1.592 \mathrm{a}$ & $1.46 \mathrm{a}$ & $1.31 \mathrm{a}$ & $1.52 \mathrm{a}$ & $1.10 \mathrm{a}$ \\
50 & $1.525 \mathrm{ab}$ & $1.32 \mathrm{~b}$ & $1.20 \mathrm{~b}$ & $1.40 \mathrm{~b}$ & $1.03 \mathrm{~b}$ \\
100 & $1.482 \mathrm{~b}$ & $1.22 \mathrm{c}$ & $1.10 \mathrm{c}$ & $1.31 \mathrm{c}$ & $.96 \mathrm{c}$ \\
150 & $1.447 \mathrm{~b}$ & $1.34 \mathrm{~d}$ & $.97 \mathrm{~d}$ & $1.22 \mathrm{~d}$ & $.90 \mathrm{c}$ \\
$\operatorname{LSD}(0.05)$ & 0.07889 & .07889 & .07438 & .08316 & .05880 \\
\hline
\end{tabular}

Table 15. Interaction effects of clones/somaclones to salinity level on $\mathrm{K}^{+}$of root in $R 2$ generation .

\begin{tabular}{|c|c|c|c|c|c|}
\hline \multirow{2}{*}{$\begin{array}{l}\text { Clones/somaclones } x \\
\text { Salinity level (mM) }\end{array}$} & \multicolumn{5}{|c|}{$\mathrm{K}^{+}\left(\mathrm{mgg}^{-1}\right)$ in root } \\
\hline & Isd 28 & Isd 35 & Isd 36 & Isd 37 & Isd 38 \\
\hline Mother $\times 0$ & $1.52 \mathrm{a}-\mathrm{d}$ & $1.41 \mathrm{abc}$ & $1.23 \mathrm{a}-\mathrm{d}$ & $1.50 \mathrm{a}$ & $.96 \mathrm{efg}$ \\
\hline Mother $\times 50$ & 1.40 cde & 1.19 ef & $1.10 \mathrm{def}$ & $1.26 \mathrm{bc}$ & $.85 \mathrm{~g}$ \\
\hline Mother $\times 100$ & $1.36 \mathrm{de}$ & $1.01 \mathrm{gh}$ & $.96 \mathrm{f}$ & $1.13 \mathrm{~cd}$ & $.72 \mathrm{~h}$ \\
\hline Mother $\times 150$ & $1.32 \mathrm{e}$ & $.91 \mathrm{~h}$ & $.81 \mathrm{~g}$ & $1.03 \mathrm{~d}$ & $.65 \mathrm{~h}$ \\
\hline $\mathrm{SC} 1 \times 50$ & $1.56 \mathrm{abc}$ & $1.23 \mathrm{def}$ & $1.21 \mathrm{a}-\mathrm{d}$ & $1.45 \mathrm{ab}$ & $1.03 \mathrm{f}$ \\
\hline $\mathrm{SC} 1 \times 100$ & $1.50 \mathrm{a}-\mathrm{d}$ & $1.13 \mathrm{fg}$ & 1.15 cde & $1.39 \mathrm{ab}$ & $.98 \mathrm{~d}-\mathrm{g}$ \\
\hline $\mathrm{SC} 1 \times 150$ & $1.48 \mathrm{a}-\mathrm{e}$ & $.97 \mathrm{gh}$ & $1.00 \mathrm{ef}$ & $1.27 \mathrm{bc}$ & $.92 \mathrm{fg}$ \\
\hline $\mathrm{SC} 2 \times 0$ & $1.58 \mathrm{abc}$ & $1.55 \mathrm{a}$ & $1.36 \mathrm{a}$ & $1.51 \mathrm{a}$ & $1.12 \mathrm{abc}$ \\
\hline $\mathrm{SC} 2 \times 50$ & $1.53 \mathrm{a}-\mathrm{d}$ & $1.49 \mathrm{ab}$ & $1.31 \mathrm{abc}$ & $1.45 \mathrm{ab}$ & $1.07 \mathrm{~b}-\mathrm{e}$ \\
\hline $\mathrm{SC} 2 \times 100$ & $1.50 \mathrm{a}-\mathrm{d}$ & $1.44 \mathrm{abc}$ & $1.18 \mathrm{bcd}$ & $1.35 \mathrm{ab}$ & $1.01 \mathrm{c}-\mathrm{f}$ \\
\hline $\mathrm{SC} 3 \times 0$ & $1.66 \mathrm{a}$ & $1.43 \mathrm{abc}$ & $1.33 \mathrm{ab}$ & $1.54 \mathrm{a}$ & $1.21 \mathrm{a}$ \\
\hline $\mathrm{SC} 3 \times 50$ & $1.61 \mathrm{ab}$ & $1.37 \mathrm{a}-\mathrm{d}$ & $1.19 \mathrm{bcd}$ & $1.43 \mathrm{ab}$ & $1.18 \mathrm{ab}$ \\
\hline $\mathrm{SC} 3 \times 100$ & $1.57 \mathrm{abc}$ & $1.31 \mathrm{~b}-\mathrm{e}$ & $1.11 \mathrm{def}$ & $1.37 \mathrm{ab}$ & $1.12 \mathrm{abc}$ \\
\hline $\mathrm{SC} 3 \times 150$ & $1.53 \mathrm{a}-\mathrm{d}$ & $1.27 \mathrm{c}-\mathrm{f}$ & $.98 \mathrm{f}$ & $1.30 \mathrm{bc}$ & $1.07 \mathrm{~b}-\mathrm{e}$ \\
\hline LSD (0.05) & 0.1578 & 0.1578 & 0.1488 & 0.1663 & 0.1176 \\
\hline
\end{tabular}

Figures with similar letter (s) don't differ significantly at $5.0 \%$ probability by DMRT

\subsection{Molecular Characterization of Selected Somaclones}

A total of 26 loci were scored using SSR primers (3). Some of them produced polymorphic bands and some produced monomorphic bands (Table 16). The three SSR primers used in the present study generated 26 amplicons. Thus, on an average 8.67 loci were amplified per SSR primer.
SSR primer UGSM 358 and UGSM 361 amplified the maximum number of 20 loci each and primer UGSM 363 amplified six loci. Amplification pattern of tissue culture raised sugarcane plantlets using SSR primer UGSM 358 is shown in Fig. 1-2, UGSM 361 is shown in Fig. 3-4 and UGSM 363 is shown in Fig. 5-6. 
Table 16. Details of SSR Primers used for detecting genetic fidelity in 33 sugarcane genotypes regenerated through tissue culture(Fig 1-6).

\begin{tabular}{|c|c|c|c|c|c|}
\hline Sl. No. & Primers & $\begin{array}{l}\text { Primer sequences } \\
\text { F- Forward primer sequences }\left(5^{\prime}-3^{\prime}\right) \\
\text { R- Reverse primer sequences }\left(5^{\prime}-3^{\prime}\right)\end{array}$ & $\begin{array}{l}\text { No. of loci } \\
\text { amplified }\end{array}$ & $\begin{array}{l}\text { No. of } \\
\text { polymorphic loci }\end{array}$ & $\begin{array}{l}\text { Range of product } \\
\text { size (bp) }\end{array}$ \\
\hline \multicolumn{6}{|c|}{ SSR Primers } \\
\hline 1 & $\begin{array}{l}\text { UGSM } 358 \\
\mathrm{Ta}=53^{\circ} \mathrm{C}\end{array}$ & $\begin{array}{l}\text { F5'ACCCTTCCCATTCCCATC3' } \\
\text { R5'CTCCAGGTTCGCCACCAC3' }\end{array}$ & 7 & 6 & 278-396 \\
\hline 2 & $\begin{array}{l}\text { UGSM } 361 \\
\mathrm{Ta}=55^{\circ} \mathrm{C}\end{array}$ & $\begin{array}{l}\text { F5'GTTCTTAGTCCAGCCGTAGTT3' } \\
\text { R5'ATCGTTGTTGTCGGTGTC3' }\end{array}$ & 13 & 13 & $176-1169$ \\
\hline 3 & $\begin{array}{l}\text { UGSM } 363 \\
\mathrm{Ta}=55^{\circ} \mathrm{C}\end{array}$ & $\begin{array}{l}\text { F5'GTTTAAGACAAGATGGTGTAGATG3' } \\
\text { R5'TACATATTTACATTGTTACTCCGC3' }\end{array}$ & 6 & 6 & $272-1197$ \\
\hline
\end{tabular}

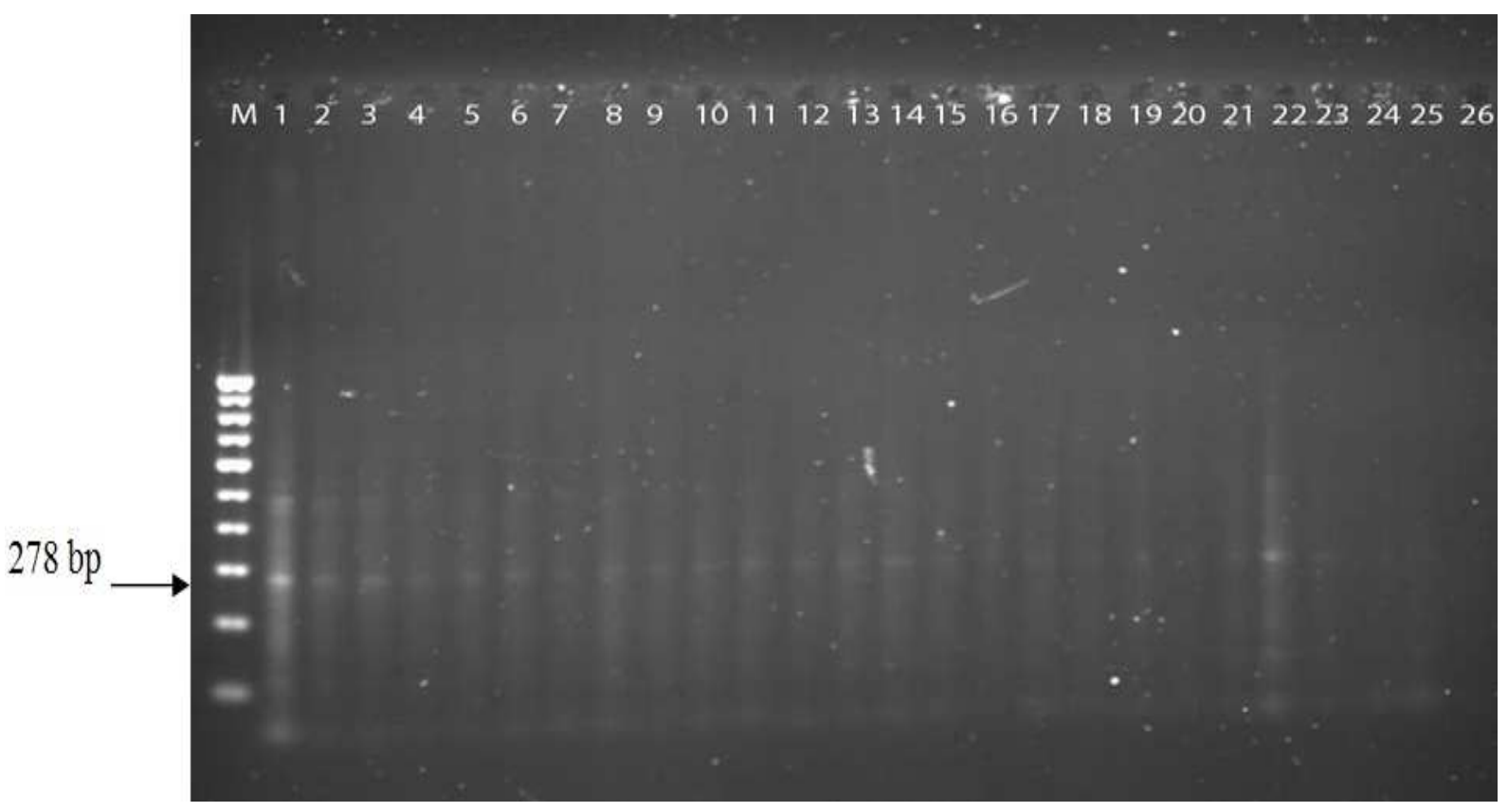

Fig. 1. SSR amplification patterns of sugarcane plantlets produced through tissue culture using UGSM 358 primer pairs. Lane M 100 bp ladder, lane 2 mother plant of the variety, lane 1-6 represent samples from regenerated plantlets of variety Isd 37, lane 7 mother plant of the variety Isd 36, lane 8-13 represent samples from regenerated plantlets of variety Isd 36, lane 14 mother plant of the variety Isd 38, lane 15-20 represent samples from regenerated plantlets of variety Isd 38, Arrow indicates the size of marker.

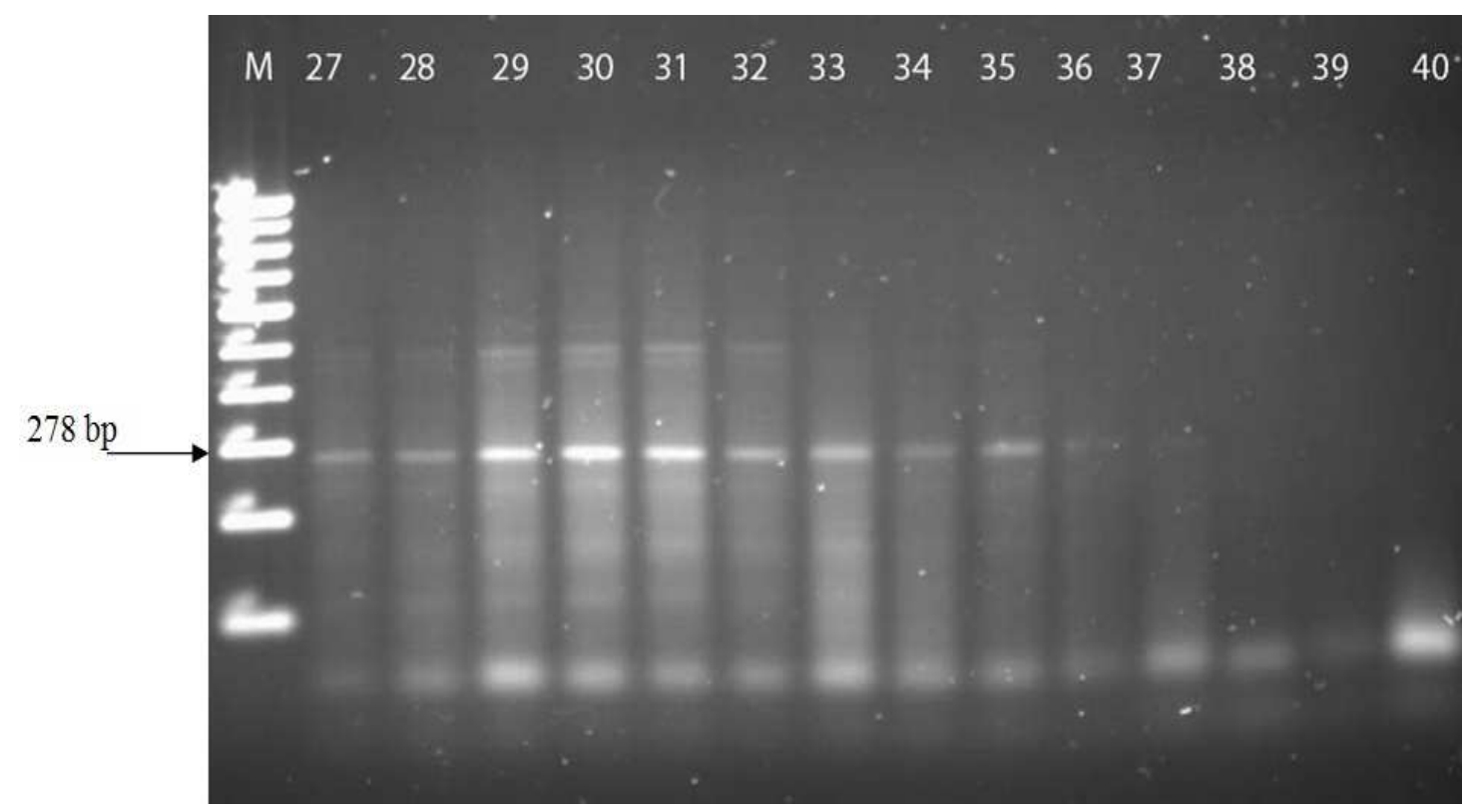

Fig. 2. SSR amplification patterns of sugarcane plantlets produced through tissue culture using UGSM 358 primer pairs. Lane M 100 bp ladder, lane 27 mother plant of the variety Isd 28, lane 28-32 represent samples from regenerated plantlets of variety Isd 28, lane 33 mother plant of the variety Isd 35, lane 34-40 represent samples from regenerated plantlets of variety Isd 35. Arrow indicates the size of marker. 


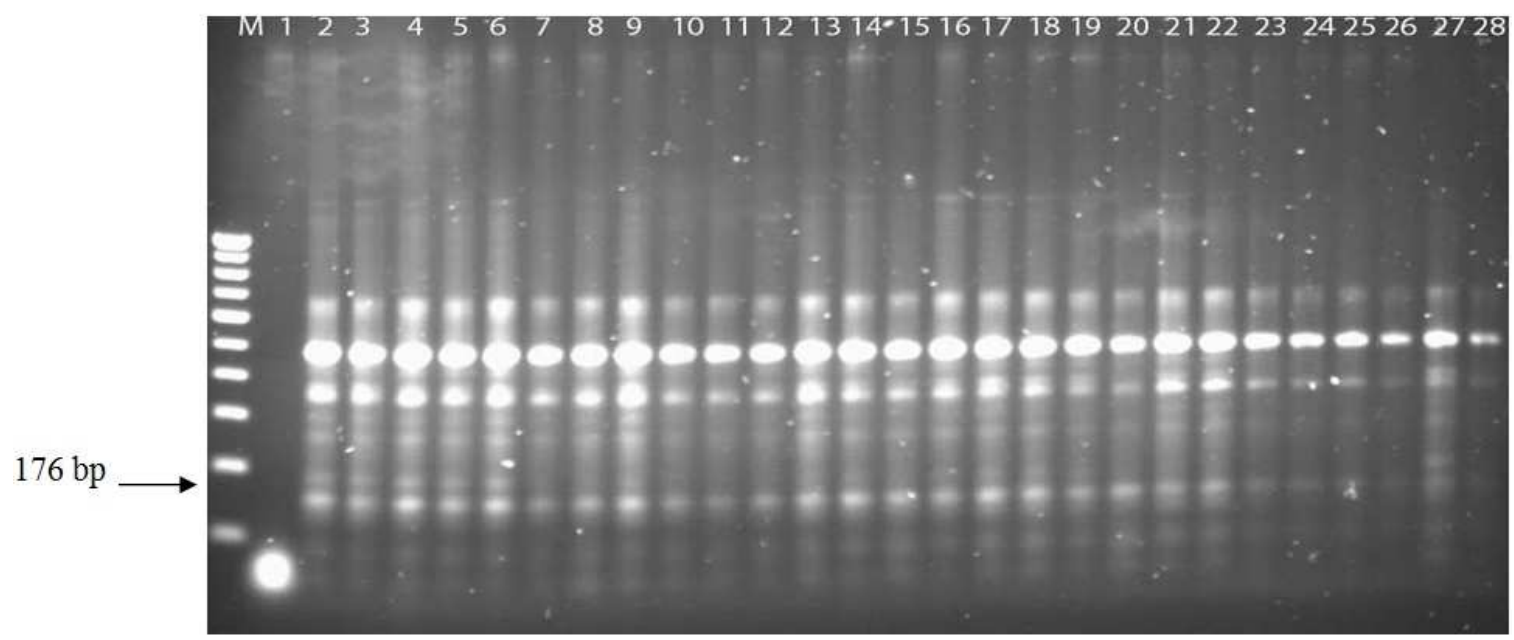

Fig. 3. SSR amplification patterns of sugarcane plantlets produced through tissue culture using UGSM 361 primer pairs. Lane M 100 bp ladder, lane 2 mother plant of the variety, lane 1-6 represent samples from regenerated plantlets of variety Isd 37, lane 7 mother plant of the variety Isd 36, lane 8-13 represent samples from regenerated plantlets of variety Isd 36, lane 14 mother plant of the variety Isd 38, lane 15-20 represent samples from regenerated plantlets of variety Isd 38. Lane 27 mother plant of the variety Isd 28, lane 28represent samples from regenerated plantlets of variety Isd 28, Arrow indicates the size of marker.

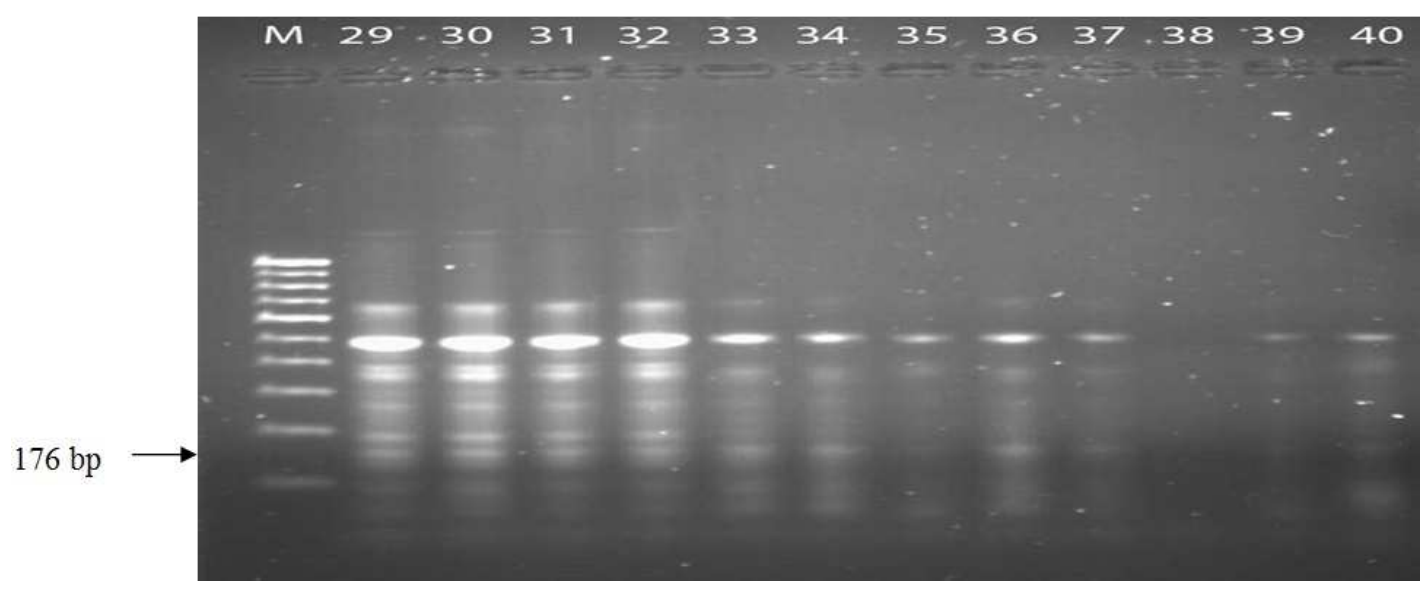

Fig. 4. SSR amplification patterns of sugarcane plantlets produced through tissue culture using UGSM 361 primer pairs. Lane M 100 bp ladder, lane 29-32 represent samples from regenerated plantlets of variety Isd 28 , lane 33 mother plant of the variety Isd 35, lane 34-40 represent samples from regenerated plantlets of variety Isd 35. Arrow indicates the size of marker.

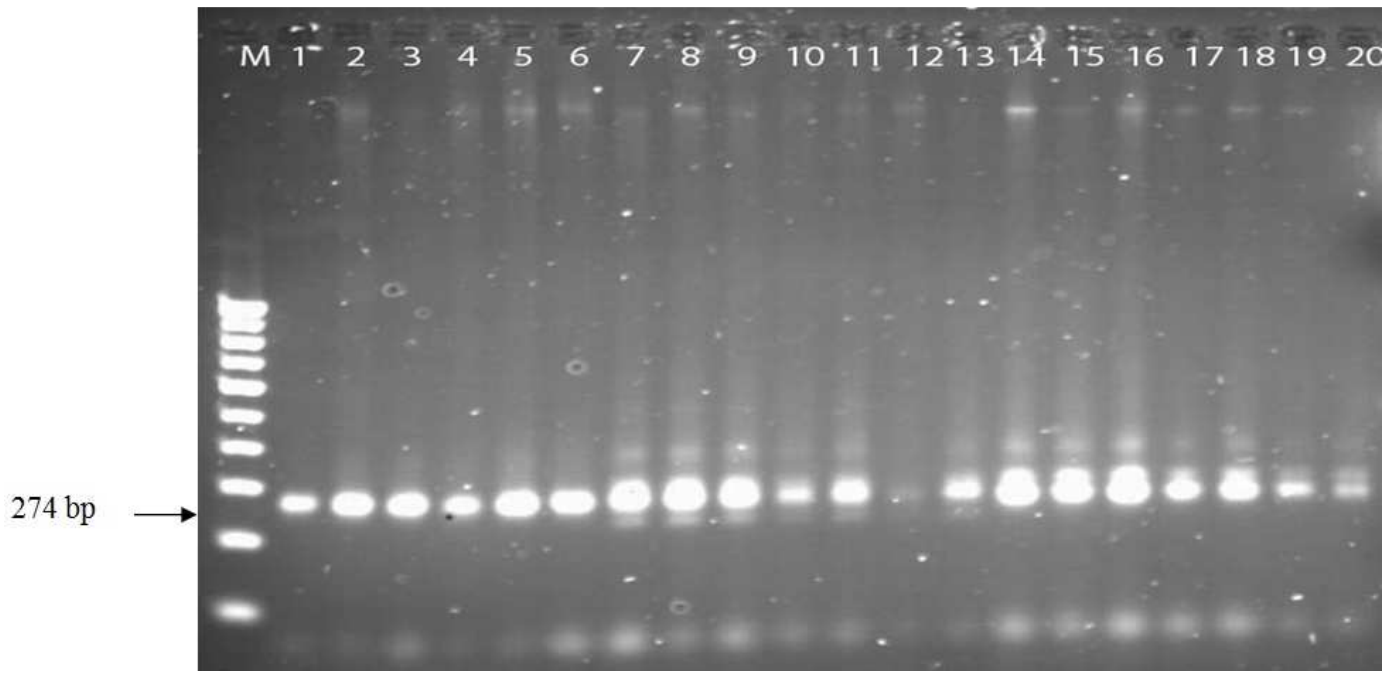

Fig. 5. SSR amplification patterns of sugarcane plantlets produced through tissue culture using UGSM 363 primer pairs. Lane M 100 bp ladder, lane 2 mother plant of the variety Isd 37, lane 1-6 represent samples from regenerated plantlets of variety Isd 37, lane 7 mother plant of the variety Isd 36, lane 8-13 represent samples from regenerated plantlets of variety Isd 36, lane 14 mother plant of the variety Isd 38, lane 15-20 represent samples from regenerated plantlets of variety Isd 38, Arrow indicates the size of marker. 


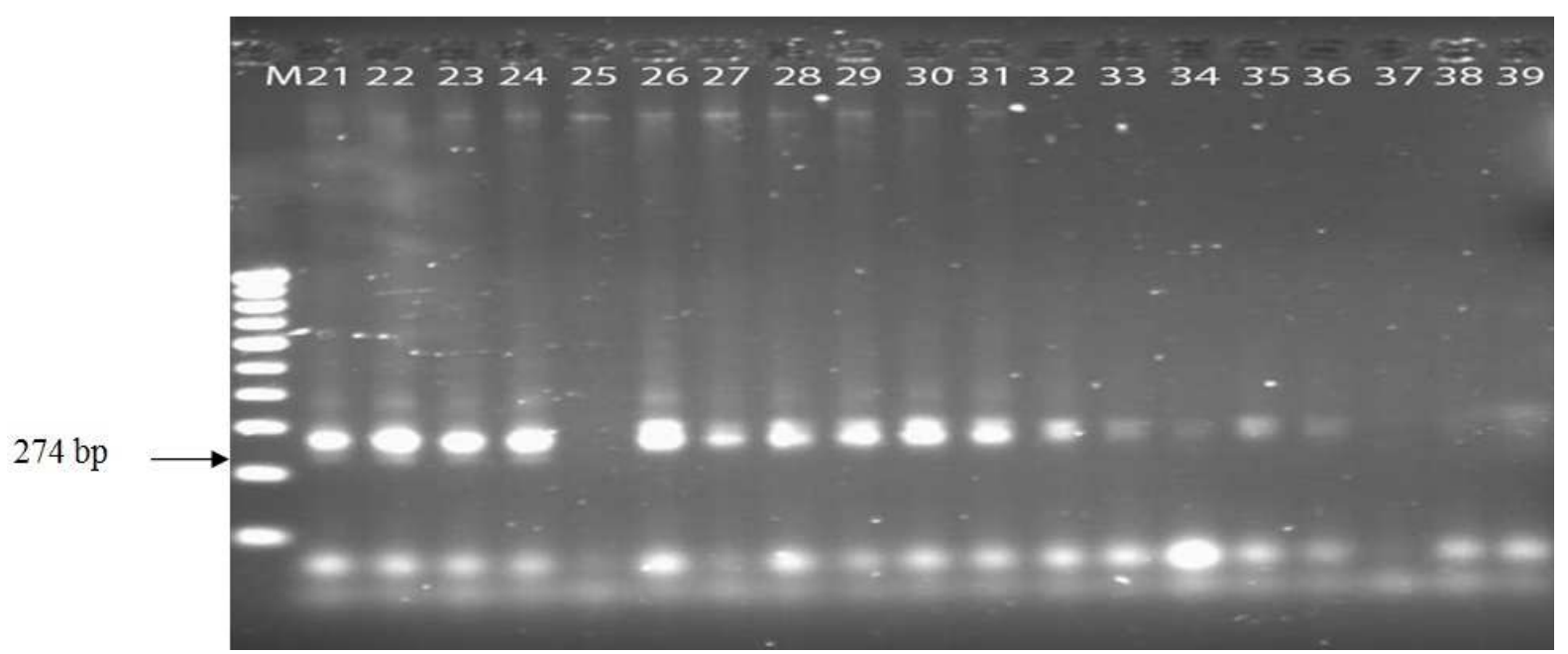

Fig. 6. SSR amplification patterns of sugarcane plantlets produced through tissue culture using UGSM 363 primer pairs. Lane M 100 bp ladder, lane 27-32 represent samples from regenerated plantlets of variety Isd 28 , lane 33 mother plant of the variety Isd 35, lane 34-39 represent samples from regenerated plantlets of variety Isd 35. Arrow indicates the size of marker.

\section{Discussion}

The increase in the concentration of proline in all the somaclones of all varieties selected from R1 generation was found to be remarkable during salinity stress of the present study in R2 generation. Increase in free proline content due to water deficit has been reported by many authors (JohariPireivatlou et al., 2010). These suggest that the production of these osmotic adjustments is a common response of plants under salinity conditions. The role of proline in adaptation and survival of plants had been observed by Watanabe et al. (2000) and Saruhan et al. (2006). In the present investigation, it was observed that a severe progressive stress in sugarcane leads more accumulation of proline as compared to control of same age group. Proline accumulates under stress conditions supplies energy for survival and growth and thereby helps the plant to tolerate stress (Aktas et al., 2007). Considering the above discussions selected somaclones of all varieties which were tested under stress may be again selected as salinity tolerant somaclones except SC1, SC2 of Isd 35 in salinity which showed lower level of proline than their mother clone under stress. The present results agree to earlier report by Kumar et al. (2011) who observed that a relation between proline content and water stress and a well developed antioxidant defense mechanism activated during water stress. The present result also agree to earlier report by Ashraf and Foolad (2007) and Kavi Kishor et al. (2005) who observed the role of proline in cell osmotic adjustment, membrane stabilization and detoxification of injurious ions in plants exposed to salt stress.

$\mathrm{NaCl}$, the dominant salt in nature, elicits two primary effects on plants: osmotic stress and ionic toxicity. Under normal condition the osmotic pressure in plant cells is higher than that in soil solution. Plant cells use this higher osmotic pressure to take up water and essential minerals in root cells from the soil solution. Under salt stress the osmotic pressure in the soil solution exceeds the osmotic pressure in plant cells due to the presence of high salt, and thus, reduces the ability of plants to take up water and minerals like $\mathrm{K}+$ and Ca2+ (Glenn et al., 1997; Munns et al., 2006). On the other hand, $\mathrm{Na}+$ and $\mathrm{Cl}^{-}$ions can enter into the cells and have their direct toxic effects on cell membranes, as well as on metabolic activities in the cytosol (Greenway and Munns, 1980; Hasegawa et al., 2000; Zhu, 2001). The in vitro stress tolerant selected somaclones of five varieties viz. Isd 28, Isd 35, Isd 36, Isd 37 and Isd 38 of present experiments showed lower level of $\mathrm{Na}^{+}$, higher level of $\mathrm{K}^{+}$both in shoot and root. Considering the above results those somalones which showed lower level of $\mathrm{Na}^{+}$ and higher level of $\mathrm{K}^{+}$were selected as salinity tolerant again. So, SC1, SC2 and SC3 of those five varieties which grown under induced salinity stress in R2 generation were selected as salinity tolerant again and those somaclones should be further trial in southern belt of Bangladesh for final selection. Our findings are in agreement with Akhtar et al. (2003) who determined the changes induced by 80 and $120 \mathrm{mM} \mathrm{NaCl}$ and observed that concentrations of $\mathrm{Na}$ and $\mathrm{Cl}$ increased and $\mathrm{K}, \mathrm{Ca}, \mathrm{Mg}, \mathrm{N}$ and $\mathrm{P}$ decreased with a rise in substrate salinity.

The total number of amplicons (26) generated in the present study using SSR markers might be sufficient to reveal somatic variations. This is evident by comparable numbers of amplified loci scored $(65,56$ and 64$)$ in various plant taxa by employing SSR-based marker assay (Leroy et al., 2000; Palombi and Damiano, 2002; Martins et al., 2004). So far there are no studies on early assessment of genetic variability among micropropagated sugarcane using SSR, SCAR-PCR analysis.

Considering the different biochemical parameters SC3 of Isd 28, SC3 of Isd 35 and SC2, SC3 of Isd 37 showed better performance under induced salinity in $\mathrm{R} 2$ generation. Those somaclones also produced polymorphic bands when we characterize with SSR markrs. So, we should recommend those lines as salinity tolerant lines for further study. 


\section{References}

[1] Aktas, L.Y.; Akca, B.T.H. and Parlak, S. 2007. Role of abscisic acid and proline treatment on induction of antioxidant enzyme activities and drought tolerance responses of Laurus nobilis L. seedlings. Fen Bilimleri Dergisi, 28:14-27.

[2] Ashraf, M. and Foolad, M. R. 2007. Roles of glycine betaine and proline in improving plant abiotic stress resistance. Environ. Exp. Bot., 59: 206-216.

[3] Akhtar, S.; Wahid, A. and Rasul, E. 2003. Emergence, growth and nutrient composition of sugarcane sprouts under $\mathrm{NaCl}$ Salinity. Biol. Plantarum, 46(1): 113-116.

[4] Bhansali, R.R. and Kishan, S. 1982. Callus and shoot formation from leaf of sugarcane in tissue culture. Phytomorphology, 32(2/3): 167-170.

[5] Evans,D.A.; Sharp, W.R. and Medmi-Filho, H.P.1984. Somaclonal and gametoclonal variation .Amer. J. Bot., 71:759-774

[6] Flowers, T. J. \& Yeo, A. R. 1995. Breeding for salinity resistance in crop plants: Aust. J. Plant Physiol. 22: 875-884.

[7] Greenway, H. and Munns, R. 1980. Mechanisms of salt tolerance in non halophytes. Annual Review of Plant Physiol. 31: 149-190.

[8] Gollek, B. 1973. Structure and function of plant cells in saline habitates-New trend in the study of salt tolerance. John Willey and Sons, New York.

[9] Glenn, E.; Brown, J. and Khan, J. 1997. Mechanisms of salt tolerance in higher plants. In: Mechanisms of environmental stress resistance in plants. (ed.), A. Basra. p. 83-110. Harwood Acad. Pub. Amsterdam.

[10] Hasegawa, P.M.; Bressan, R.A.; Zhu, J.K. and Bohneert, H.J. 2000. Plant cellular and molecular responses to high salinity. Annual Rev. Plant Physiol. Plant Mol. Biol., 51: 463-499.

[11] Heinz, D.J.; Krisnamurti, M.K.; Nickell, L.G and Maretzki, A.1995. Cell, tissue and organ culture in sugarcane improvement. Plant Cell Tissue Organ cult., Narosa Pub., New Delhi.

[12] Johari-Pireivatlou, M.; Qasimov, N. and Maralian, H. 2010. Effect of soil water stress on yield and proline content of four wheat lines. African J. Biotechnol., 9: 036-040.

[13] Kader, M. A. 2006. Salt Stress in Rice: Adaptive Mechanisms for Cytosolic Sodium

[14] Homeostasis. Ph.D Thesis. Dep. Plant Biol. Forest Genet. Swedish University of Agricultural Sciences .Uppsala. Sweden.

[15] Kavi Kishor, P.B.; Sangam, S.; Amrutha, R.N.; Sri Laxmi, P.; Naidu, K.R.; Rao, K.R.S.S.; Rao, S.; Reddy, K.J.; Theriappan,
P. and Sreenivasulu, N. 2005. Regulation of proline biosynthesis, degradation, uptake and transport in higher plants: Its implications in plant growth and abiotic stress tolerance. Curr. Sci., 88: 424-438.

[16] Kumar, R. R.; Karajol, K. and Naik, G. R. 2011. Effect of polyethylene glycol induced water stress on physiological and biochemical responses in pigeonpea (Cajanus cajan L. Millsp.). Recent Res. Sci. Technol., 3(1): 148-152.

[17] Liu, M.C.; Huang, Y.J. and Shih, S.C. 1972. The in vitro production of plants from several tissues of Saccharum spp. J. Agric. Ass. China, 77: 52-58.

[18] Leroy X.J.; Leon, K. and Charles, G. 2000. Cauliflower somatic embryogenesis and analysis of regenerants stability by ISSRs. Plant Cell Rep., 19:1102-1107.

[19] Martins, M.; Sarmento, D. and Oliveira, M.M. 2004. Genetic stability of micropropagated almond plantlets as assessed by RAPD and ISSR markers. Plant Cell Rep., 23: 492-496

[20] Martinez-Beltran J. and Manzur C.L. 2005. Overview of salinity problems in the world and FAO strategies to address the problem. Proc. Int. Salinity Forum, Riverside, California, April 2005, p. 311-313.

[21] Munns, R.; James, R.A. and Läuchli, A. 2006. Approaches to increasing the salt tolerance of wheat and other cereals. J. Exp. Bot., 57: 1025-1043

[22] Pessarakli, M.1999. Handbook of Plant and Crop Stress. 2nd Edn. Revised and Expanded, Marcel Dekker, p. 1254. Inc., New York.

[23] Palombi, M.A. and Damiano, C. 2002. Comparison between RAPD and SSR molecular markers in detecting genetic variation in kiwifruit Actinidia deliciosa A. Chev. Plant Cell Rep., 20: 1061-1066

[24] Saruhan, N.; Terzi, R. and Kadioglu, A. 2006. The effects of exogenous polyamines on some biochemical changes during drought stress in Ctenanthe setosa. Acta Biologica Hungarica, 57(2): 221-229.

[25] Shahanawaz, R. M. S. 2006. DNA isolation, quantification and fingerprinting using RAPD markers of sugarcane (Saccharum officinarum L.). M. Sc. Thesis. Biotechnol. Gen. Engineer. Dept., Islamic Univ., Kushtia, Bangladesh.

[26] Singh R.K.; Singh R.B.; Singh S.P. and Sharma M.L. 2011. Identification of sugarcane microsatellites associated to sugar content in sugarcane and transferability to other cereal genomes. Euphytica, 182: 335-354

[27] SRDI, 2003. Soil salinity in Bangladesh 2000. Soil Resource Development Institute Watanabe, S.; Kojima, K.; Ide, Y. and Satohiko, S. 2000. Effects of saline and osmotic stress on proline and sugar accumulation in Populus euphratica in vitro. Plant Cell Tissue Organ Cult., 63(3): 199-206.

[28] Zhu, J. K., 2001. Plant salt tolerance. Trends Plant Sci., 6, 6671. 